\title{
EL DISCURSO MODERNISTA Y LA DIALECTICA DEL EROTISMO Y LA CASTIDAD
}

Un poema de Ricardo Jaimes Freyre

POR

OSCAR RIVERA-RODAS

Louisiana State University

\section{EL LENGUAJE MODERNISTA}

Por la elaboración sensorial de su aspecto expresivo y por la dilección hedonista de su aspecto temático, es un discurso auténticamente senstral. Por eso suele ser representado por el discurso erótico. El reconocimiento de ese carácter es unánime en el consenso de la crítica. En este ensayo, sin embargo, me ocuparé del discurso que trata específicamente el tema erótico. El análisis del mismo permitirá realizar, sin restricciones, un estudio más amplio de los rasgos peculiares del lenguaje modernista, motivo principal de esta tarea.

La poesía erótica es una forma evidente de discurso persuasivo, mediante el cual el destinador se dirige a su destinatario en una actitud dialógica de función conativa (en el sentido de Jakobson en Ensayos de lingüística general. Barcelona: Planeta, 1985). En su aspecto linguiístico debe emplear, indefectiblemente, el vocativo y el imperativo. Sin embargo, tanto su aspecto temático como la intención del destinador varían de acuerdo al código cultural de las épocas, lo cual marca esenciales diferencias en los discursos eróticos de cada período literario. Así, en la poesía hispanoamericana de fines del siglo xix, el discurso erótico modernista instituye un nuevo modelo con relación al discurso erótico romántico, lo que no significa que rechace las manifestaciones que le antecedieron. Intentaré realizar una caracterización somera de ambos modelos antes de realizar el análisis específico del discurso erótico modernista. 


\section{Discurso ERÓtico ROMÁNTICO Y MODERNISTA}

Frente al discurso erótico sentimental del romanticismo, dominado fuertemente por las categorías cristiano-católicas de la virtud y el pecado, el modernismo introduce un discurso erótico sensual y lascivo francamente desafiante de los valores del catolicismo. Para el romanticismo, el concepto del amor está ligado a la idea de la consagración sacramental indisoluble; por eso es aceptado como una manifestación divina o del destino. Para el modernismo, el amor es simplemente un goce libre y casual. Mientras el primero expresa o excita sentimientos tiernos y castos, el segundo mueve al juego hedonista y lujurioso.

\section{El enunciador romántico}

El enunciador romántico ha demostrado una actitud definida de alusión e ilusión frente a los referentes sensuales. Los ha aludido apenas o los ha eludido completamente de su discurso. Cuando las alusiones refieren sentimientos de ardor, fuego o estremecimiento, se hacen en contraste con los sentimientos de frialdad, hielo y pasividad; es decir, del amor frente al desamor. Las descripciones corporales tienen sus límites en el ropaje de los actantes. Inmerso en la concepción cristiana, el amor es una virtud definida por su pureza y castidad. El enunciador romántico es muy consciente de semejantes códigos culturales, por los cuales prescinde de toda alusión al amor físico:

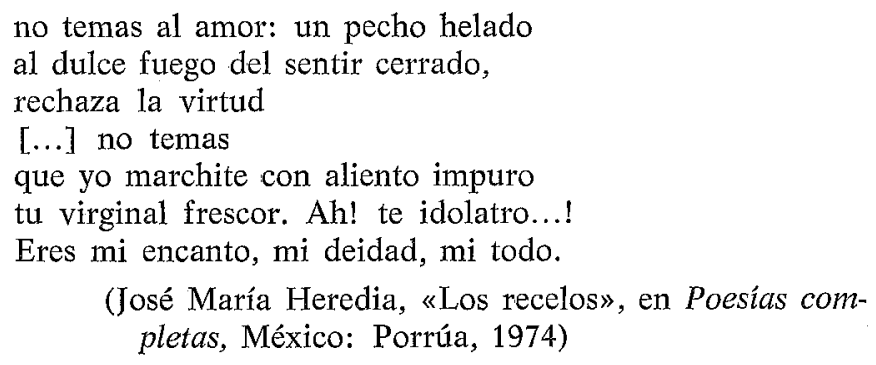

(José María Heredia, «Los recelos», en Poesías completas, México: Porrúa, 1974)

El enunciador romántico elude toda referencia concupiscente, pues el espíritu no debe establecer diálogo o comunicación con el cuerpo. El amor debe mostrarse siempre inocente, libre de culpa, en el sentido cristiano, espiritual e ideal. No obstante, aunque contradictorio en su fidelidad a la ideología católico-cristiana dominante, el acto de amar es, en la mayoría de los casos, un acto de idolatrar por el cual se diviniza al ser ama- 
do: implica un culto personal, una conducta religiosa paralela, aunque subalterna del cristianismo, que introduce entre los amantes una distancia sagrada. Rafael Pombo escribía: «iTú y Dios me disputáis en este instante!» ${ }^{1}$. El amor, como sentimiento religioso de virtud, modestia y recato, es sobre todo ideal. El primer romántico hispanoamericano, Heredia, en un texto de 1927 («A mi amante»), describe del siguiente modo a su amada en el lecho: «Es medianoche: vaporosa calma / y silencio profundo / el sueño vierte al fatigado mundo / y yo velo por ti, mi dulce amante.» Toda connotación sensual es anulada por el propio texto, que describe la típica contemplación romántica: «yo tu hermosura / en un silencio religioso admiro» $[\ldots] \ll \mathrm{O}$ al escuchar cuando tu boca pura / y tímida confiesa / el inocente amor que yo te inspiro».

Uno de los textos que mejor sintetizan los aspectos del discurso que voy discutiendo es «Mi amada en la misa de alba», de José Joaquín Pesado (Poesías originales y traducidas. México, 1840). La relación erótica romántica somete discriminadamente los aspectos señalados a una ordenación espacial disociada en dos subespacios que representan lo elevado/ lo bajo, lo empíreo/lo terreno, lo puro/lo inmundo, categorización originada en valores claramente cristianos. El enunciador amante continúa: «Me parece que eres ángel / que al trono de Dios asiste.» Obviamente, la descripción y la definición del ser querido deben realizarse según semejante categoría topológica, que garantiza no sólo el distanciamiento, sino también el límite mutuo e impenetrable de ambos subespacios implícitos en la comunicación erótica ${ }^{2}$. La estructura topológica del texto simboliza la estructura del espacio ético de la relación erótica. El enunciador de Pesado prosigue su discurso, aunque alerta en su fidelidad a la ideología religiosa local, para evitar el culto a la persona amada: «iEres bella, ingenua, pura, / reinas en una altura / harto superior a mí! [...] Si gentil hubieras sido, / altares te levantara, / la rodilla doblara, / y fueras mi diosa tú.» En fin, la persuasión del discurso erótico romántico se manifiesta, en la generalidad de los casos, sobre la base de las convenciones que identifican el amor con la modestia y el recato, así como la entrega amorosa con el matrimonio:

${ }^{1} \mathrm{H}$. G. Schenk, en su estudio sobre el romanticismo europeo, afirma que «Semejante confusión entre el amor sagrado y el profano prevalece en gran parte del pensamiento romántico» (El espíritu de los románticos europeos, trad. de J. J. Utrilla. [México: F. C.E., 1983], p. 200).

${ }^{2}$ Yuri M. Lotman señala muy bien que el rasgo topológico fundamental del espacio en el texto es el limite. «El límite divide todo el espacio del texto en dos subespacios que no se intersectan recíprocamente. Su propiedad fundamental es su impenetrabilidad» (Estructura del texto artístico, trad. de Victoriano Imbert [Madrid: Istmo, 1978], p. 181). 
Déjame unir mis labios a tus labios, une a tu corazón mi corazón; doblemos nuestro ser para que alcance a recoger la bendición de Dios.

(Rafael Pombo, «Noche de diciembre», en Poesias completas. Madrid: Aguilar, 1957)

\section{El enunciador modernista}

El enunciador modernista del discurso erótico introduce el desnudo y la descripción deleitosa y concupiscente del cuerpo humano. Uno de los primeros textos del desnudo lo ofrece, aunque con efecto instantáneo, Salvador Díaz Mirón en "Vigilia y sueño» (Poesías completas. México: Porrúa, 1947). Ya desde el título el texto plantea el enfrentamiento de dos planos, que no ordenan la realidad como parece a simple lectura, sino que la disocian. Bien pueden ser considerados dos discursos dialécticos y dialógicos. El enunciador emplea conscientemente valores del código romántico para enfrentarlos con los de otro código aún inédito (el modernismo) en la tradición hispanoamericana de la lírica erótica. Transcribiré las estrofas $[a]$ segunda y $[b]$ quinta del texto, que refieren la anécdota del forcejeo amoroso de una pareja de jóvenes prometidos («la moza lucha con el mancebo»). La muchacha se zafa.

\section{[a] Y huye sin mancha y sin deterioro en la pureza y en el decoro, y es un gran lirio de nieve y oro.}

La muchacha deambula entre las sombras del jardín y gana al cabo su cuarto. Dentro de su habitación, sonríe, aunque con un dejo amargo, ante el espejo. Cierra las puertas

[b] Y echa cerrojos, y se desnuda, y al catre asciende blanca y velluda, $\mathrm{y}$ aun desvestida se quema y suda.

La lectura semiótica de este texto no puede dejar de explicitar dos tipos de blancura en el actante erótico («la moza»), que representan los modelos de erotismo en contraste. Por una parte, en $[a]$, de pureza y decoro; por otra, en $[b]$, desnuda y blanca. La primera blancura es abstracta: sin mancha; la segunda es corpórea: la piel blanca en oposición con la oscuridad del pubis: velluda. Una, ilusoria: gran lirio de nieve $y$ oro. Otra, humanizada: aun desvestida se quema y suda. Tal es el tránsito evidente de un 'texto del ideal' a un 'texto del cuerpo', del erotismo espi- 
ritual al erotismo carnal, del discurso romántico al discurso modernista. El texto deja al lector la resolución del conflicto, que emerge de una realidad disociada, cuya dialéctica es referida por el contraste irónico de las categorías semánticas pureza/sensualidad por un lado y vigilia/sueño por el otro. El final es deliberadamente violento:

$\mathrm{Y}$ duerme a poco. $\mathrm{Y}$ en un espanto, $y$ en una lumbre, $y$ en un encanto, forja un suceso digno de un canto.

iSueña que yace sujeta y sola en un celaje que se arrebola, y que un querube llega y la viola!

La estrofa final, además de señalar la liberación del deseo contenido de «la moza», proyecta el sueño a la zona celestial de la mitología judeocristiana habitada por serafines (querubes). De este modo, el texto ironiza algunos aspectos del código romántico, que empleaba frecuentemente esa zona celestial para representar el lugar más seguro para la preservación de la pureza y la castidad.

En oposición al amor puro y casto del romanticismo, el modernismo propone, asimismo, el «impuro amor de las ciudades», de acuerdo a la definición de Julián del Casal, que en uno de sus textos confiesa: «Nunca a mi corazón tanto enamora / el rostro virginal de una pastora, / como un rostro de regia pecadora» («En el campo», en Poesías completas. Ed. M. Cabrera Saqui. La Habana: Ministerio de Educación, 1945). Se prefiere el goce lascivo y concupiscente sobre el cándido e inocente. Del Casal enumera así también sus amores: «Amo el bronce, el cristal, las porcelanas, / las vidrieras de múltiples colores, / los tapices pintados de oro y flores / y las brillantes lunas venecianas.» Es decir, los lujos. Y su enumeración pasa del lujo a la lujuria:

y el lecho de marfil, sándalo y oro,

en que deja la virgen hermosura

la ensangrentada flor de su inocencia.

(«Mis amores»)

A su vez, Darío desarrolla a plenitud, a partir de Azul (Poesías completas. Madrid: Aguilar, 1967) el nuevo modelo del discurso erótico en sus manifestaciones explícitamente sensuales y sexuales. La perfección del amor ya no radica en el candor y la pureza, sino en la experiencia y en la erudición de la práctica hedonista y sensual. De ahí que Darío incite a amar al modo griego, francés, alemán, español, chino, japonés, hindú... 
Amor cosmopolita, universal y múltiple, que socave toda la tradición, incluyendo a la mitología bíblica sobre la que se basa el cristianismo. Por eso habla de un amor capaz de asombrar inclusive a la serpiente del paraíso, inspiradora del pecado: «Amor, en fin, que todo diga y cante, / amor que encante y deje sorprendida / a la serpiente de ojos de diamante / que está enroscada al árbol de la vida» («Divagación»). Darío rechaza el concepto del amor-virtud al que fue sometida la relación humana por la ideología cristiano-católica, e instituye conscientemente la versión 'profana' del amor. No en vano estos versos corresponden a sus Prosas profanas, título al que Octavio Paz calificó también de «erudito y profano», a tiempo de explicar que esa «confusión deliberada» era una «persistente inclinación de Darío y otros poetas» para expresar «la alternativa fascinación y repulsión que experimenta la poesía moderna ante la religión tradicional» (Cuadrivio. México: Joaquín Mortiz, 1965, pp. 36-37) ${ }^{3}$. Darío celebra franca y explícitamente la unión sexual:

Tu sexo fundiste

con mi sexo fuerte,

fundiendo dos bronces.

(«Mía»)

Sin embargo, pese a su actitud consciente y deliberada con respecto al tema erótico, el modernismo trasciende siempre los hechos para reconocer el trasfondo metafísico de los mismos, aunque cifrado y enigmático. Para Darío, la mujer «concentra el misterio del corazón del mundo»; asî también «la rosa sexual / al entreabrirse / conmueve todo lo que existe, / con su efluvio carnal / y con su enigma espiritual» (Cantos, XXIII). Paz ha afirmado que la cosmología de Darío «culmina en un misticismo erótico» (Cuadrivio, p. 57) ${ }^{4}$. Esta dualidad típica del discurso erótico

${ }^{3}$ Tampoco es casual que Pedro Salinas haya reaccionado desde su sensibilidad cristiana ante el discurso erótico de Darío, denunciando al homo carnalis, además de conductas «sacrílegas» en el poeta (La poesia, pp. 65-66). Keith Ellis es uno de los críticos que ha rectificado, por otra parte, algunos de los equívocos de Salinas. Escribió que lo ideal y lo sensual en Darío «no son antitéticos ni se excluyen. Lo espiritual y lo sensual son aspectos complementarios del ideal de poeta» («Un análisis estructural del poema 'Venus', de Darío», en Revista Iberoamericana, vol. 33, núm. 64 [julio-diciembre 1967], p. 254).

${ }^{4}$ Graciela Palau de Nemes ha desarrollado este concepto (el «misticismo de lo erótico») en un ensayo de amplia visión de la poesía hispánica, en el que señala con acierto que el modernismo «intuyó una posible trascendencia del ser que nada tuviera que ver con la tradicional trascendencia del espíritu, en lo que ha venido a ser un misticismo poético de la carne» («Tres momentos del misticismo de lo erótico en la poesía del siglo xix: Darío, Jiménez y Paz», en Homenaje a Rubén Dario, ed. A. Sánchez-Reulet [Los Angeles: University of California Press, 1970], p. 218). 
modernista, carnal y metafísica a un tiempo se ha extendido hasta Delmira Agustini, quien la desarrolló con vigor extraordinario. «El cisne» es un texto en el que, desde la perspectiva femenina, revive la experiencia de Leda:

Pero en su carne me habla
y yo en mi carne le entiendo.
-A veces itoda! soy alma;
y a veces itoda! soy cuerpo-.
Hunde el pico en mi regazo
y se queda como muerto
[...]
el cisne asusta de rojo,
y yo de blanca doy miedo!

\section{UN TEXTO PARADIGMÁTICO}

Es necesario detener este análisis en un texto específico. Considero que «Voz extraña...» es un poema paradigmático de la manifestación literaria erótica. Su autor, Ricardo Jaimes Freyre (Bolivia, 1866-1933), es uno de los poetas mayores del modernismo, que además ha cultivado con especial dilección el discurso erótico. La concepción erótica del modernismo, que he señalado someramente en los párrafos anteriores, la analizaré ahora en profundidad. Uso la edición de Castalia bárbara (Buenos Aires: Juan Schürer-Stolle, 1899).

Aunque la persuasión es un recurso antiguo, ya empleado por los sofistas para convencer al oyente o al interlocutor de lo que se proponía o debía ser acepado, sólo con la Retórica de Aristóteles se convierte en objeto de estudio y observación sistemáticos. E1 texto de Jaimes Freyre emplea los dos medios de persuasión señalados por el manual aristotélico: los artísticos (proporcionados por el orador) y los no artísticos (proporcionados por pruebas externas). Asimismo, de los tres tipos de persuasión que reconoce la retórica - los que surgen de las cualidades del orador (ethos), de las emociones del oyente (pathos) o de los lugares comunes o tópicos (topoi) - el texto de Jaimes Freyre demuestra en su estructura el primero y el tercero. Por otra parte, la persuasión erótica del poeta boliviano, en su proceso de argumentación y demostración, sigue el modelo del silogismo retórico (enthymema). Estos aspectos obligarán a prestar cierta atención a la retórica, aunque sólo parcialmente, durante el desarro1lo de este análisis, cuyo objetivo es básicamente doble: describir a la vez el discurso erótico en el modernismo y las características propias del len- 
guaje modernista. Así, este trabajo estudiará el enunciado, la enunciación (y el papel del enunciador/enunciatario), el simulacro de la comunicación (y el papel del destinador/destinatario), dentro del cual se verá el tema erótico en su pugna entre el deseo y el miedo, dando lugar a una estructura dialógica, en su función conativa como asedio insistente manifestado por la re-escritura y metatextualidad y, finalmente, en su relación intertextual con otros discursos de la tradición literaria.

«Voz extraña...» puede ser segmentado para su análisis en tres partes: el exordio, integrado por los versos 1-11; la argumentación, versos 12-39, y la prueba, versos 40-53, que es un enthymema obtenido de la tradición antigua de los topoi. Las divisiones coinciden con dos versos anafóricos y recurrentes repetidos al término de cada segmento, que coadyuvan en las marcas de la segmentación.

\section{EXORDIO: ENUNCIACIÓN Y COMUNICACTÓN}

El primer término (exordio) de la segmentación que propongo es el siguiente:

1 Voz dulcísima y extraña, que murmura extrañas cosas, por los sueños de la virgen ignoradas... Que penetra en sus oídos, suavemente,

5 como una caricia musical y vaga; como una harmonía que se enredara en sus trenzas, blondas y largas y a través del oro crespo de la trenza, en sus oídos resonara.

10 Desfallece como un crepúsculo en el eco de las palabras.

Dada la función conativa del discurso erótico, es decir, «la orientación hacia el destinatario», como define Jakobson (Ensayos, p. 355), es necesario analizar la instancia de la enunciación y el esquema de la comunicación en que se produce ese discurso, a fin de reconocer mejor la actitud del enunciador y destinador del mismo.

\section{Enunciación: el enunciador/enunciatario}

El análisis inicial enfocará la instancia lingüística y lógicamente presupuesta en la que se produce ese enunciado, es decir, la enunciación. La 
estructura general de la enunciación, al margen de los rasgos específicos que puede presentar cada discurso, se ordena de acuerdo al comportamiento del sujeto de la enunciación, que abarca las posiciones de dos actantes implícitos: el enunciador y el enunciatario. Ambas posiciones, que convergen en una función sincrética de destinador/receptor, participan en la producción del enunciado ${ }^{5}$. El segmento transcrito carece de un sujeto explícito de la enunciación, de un «yo» que pueda ser identificado por los rasgos propios de su enunciación. Ese aspecto obvio del texto permite reconocer y estudiar al enunciador/enunciatario implícito.

Ese sujeto en el texto de Jaimes Freyre mantiene una actitud metalinguística consciente, que le permite valorar constantemente la eficacia de su propio enunciado-discurso, cuyo objeto es incitar al acto amatorio. Su discurso incitativo debe apoyarse en dos términos encontrados: la sorpresa y el deseo, que en el texto se configuran como lo dulce y lo extraño. Con estas categorías, además, se identifican al enunciador por un lado, pues incita al deseo, y al enunciatario por otro, que reconoce asimismo (en su papel de primer 'lector' del texto) la índole extraña (para una virgen) de la misma incitación. Así, el sujeto de la enunciación se apoya en ambas instancias: a) por una parte, en la presuposición del enunciador de que el discurso de la incitación será dulce, por atractivo, para la receptora explícita del mensaje (la mujer virgen); b) por otra, en la presuposición del enunciatario de que dicho discurso será extraño, por desconocido, para la misma receptora. De ahí que el texto haga énfasis en un paralelismo semántico de ambas experiencias encontradas: el rechazo de lo extraño y la atracción de lo dulce. En efecto, la predicación del primer verso establece una categoría semántica de atracción/rechazo que organiza la estructura dialéctica del texto sobre dos ejes sintagmáticos, paralelos y complemenarios, que en la superficie se manifiestan como oposición: [a] la atracción de lo dulce (philia) y [b] el rechazo de lo extraño (phobia). Así, tenemos estos dos conjuntos de isotopías semánticas:

[a] dulce (v. 1), suavemente (v. 4), penetra en sus oídos como una caricia musical (vv. 4-5).

${ }^{5}$ Emile Benveniste señaló que el locutor, en cuanto «asume la lengua, implanta al otro delante de él, cualquiera que sea el grado de presencia que atribuya a ese otro. Toda enunciación es, explícita o implícita, una alocución, postula un alocutario» (Problemas de lingüistica general, trad. de Juan Amela [México: Siglo XXI, 1977], p. 85). Por otra parte, Greimas y Courtés afirman claramente que «el enunciatario no es solamente el destinatario de la comunicación, sino también el sujeto productor del discurso, al ser la 'lectura' un acto de lenguaje (un acto de significar) muy similar al de la producción, propiamente dicha, del discurso» (Semiótica. Diccionario razonado de la teoría del lenguaje, trad. de E. Ballón Aguirre y H. Campodónico Carrión [Madrid: Gredos, 1982], p. 148). 
[b] extraña (v. 1), extrañas cosas (v. 2), ignoradas por los sueños de la virgen (v. 3).

Sin embargo, frente a esa oposición, la figuración del sujeto del enunciado (la voz) como término musical (caricia musical, harmonía) garantiza el equilibrio de la aparente contraposición. Así, la categoría extraño/ dulce es percibida como expresión musical y el discurso incitativo se convierte en texto musical. Se puede afirmar también que, en el nivel de la comunicación entre los dos actantes empíricos (emisor y receptor), el discurso erótico y voluptuoso es música.

El discurso incitativo como texto de música no es del todo celebratorio, pues conlleva duda. El análisis sintagmático del primer segmento permite observar tres momentos identificados por sus diferencias verbales (indicativo-subjuntivo-indicativo), y que equivalen a tres fases y modos del proceso enunciativo.

[1] Los cinco primeros versos apoyan su sentido en el presente del indicativo: murmura (v. 2), penetra (v. 4) como una caricia musical.

[2] Los cuatro versos siguientes lo hacen sobre el pretérito imperfecto del subjuntivo: se enredara (v. 7), resonara (v. 9) como una harmonía.

[3] Los dos últimos versos del segmento retoman el tiempo del presente indicativo: desfallece (v. 10) el eco de las palabras.

$\mathrm{Si}$ bien los verbos del primer momento refieren la realidad y certidumbre de la acción incitativa, los verbos del segundo momento, dentro del modo subjuntivo, demuestran irrealidad e incertidumbre. Si el primero refiere la acción de la voz en proceso de realización del deseo incitativo, el segundo, aunque con el mismo frenesí de la persuasión, implica poca confianza en el cumplimiento del deseo. De este modo, la categoría semántica que estructura la enunciación enfrenta dos fuerzas contrarias, cuyos sentidos pueden ser identificados por: realidad y certidumbre versus irrealidad e incertidumbre, lo que es lo mismo a: deseo versus escasa esperanza de lograrlo.

El plano profundo de esta categoría muestra duda e inseguridad, permite discutir la eficacia de la persuasión amorosa, discusión que no tarda en demostrar sus resultados. La voz, si bien murmura y penetra suavemente, no consigue el efecto esperado: ni se enreda en la cabellera ni resuena en los oídos de la virgen. La repercusión y resonancia del sonido y su propagación en el cuerpo de la mujer no se cumple del modo deseado. De ahí que la enunciación pasa a su tercer momento. La frustración del deseo se acentúa en el verso final del segmento. El eco de la voz no sólo no resuena ni se propaga en el cuerpo de la amada, sino que permanece 
fuera de ella, en el exterior: integrado al crepúsculo, que decae y disminuye sus fuerzas paulatinamente: desfallece.

Los tres momentos analizados de este segmento pueden ser resumidos por tres proposiciones que definen el proceso de la enunciación en el nivel semántico:

[1] deseo (vv. 1-5).

[2] duda (vv. 6-9).

[3] fracaso (vv. 10-11).

E1 proceso enunciativo diseña un recorrido de paulatina degradación. Este aspecto lleva a analizar la estructura del enunciado ya no en la instancia de la enunciación, como lo he hecho hasta ahora, sino dentro del esquema de la comunicación simulada, a cargo de sus actantes implícitos: el destinador y el destinatario.

\section{Comunicación: dialogismo de «philia» $y$ «phobia»}

E1 primer segmento es una descripción de la función persuasiva de la palabra. Privilegia, obviamente, el aspecto expresivo: la voz y la palabra como instrumentos de la provocación voluptuosa dirigida a una mujer que desconoce el comercio sexual: una virgen. Este actante, como destinatario explícito del simulacro de comunicación, determinará asimismo las características del discurso. La extrañeza de la voz (la palabra incitante), referida por el ahora destinador, está en relación con la recepción del mensaje por la mujer virgen, que no responde a la incitación voluptuosa porque, precisamente, desconoce la experiencia del amor sensual.

Desde el punto de vista de la comunicación, la duda expresada por el destinador mediante la modalidad subjetiva tiene sus antecedentes extratextuales y anteriores a todo enunciado: en el destinatario. Porque este discurso del deseo (philia) dirigido por el destinador (el amante) no es más que una reacción y réplica a otro presupuestamente enunciado por el destinatario (la virgen): el discurso del rechazo y del temor (phobia) ${ }^{\circ}$. Así se entiende lo que Bajtín señala cuando afirma que toda «obra se relaciona con otras obras-enunciados: con aquellos a los que contesta y aquellos que le contestan» (La estética de la creación verbal. México: Siglo XIX, 1982, p. 265). El discurso del amante concupiscente es una respuesta al rechazo de la amada, que permanece inalterada y casta, ratificando su estado virginal. La misma definición de virgen define ese estado

\footnotetext{
${ }^{6}$ Esta categoría, que me parece útil emplearla en este caso, fue propuesta por Robert Blanché (véase Greimas y Courtés, Semiótica, p. 116).
} 
incambiable (anterior y posterior al enunciado de la incitación). Por tanto, la argumentación erótica, en este caso, es una respuesta al texto impasible de la virginidad, el cual, al mismo tiempo, provoca la duda y después la frustración del discurso erótico y su incitación al goce carnal.

El deseo, definido como el movimiento enérgico de la voluntad hacia el conocimiento, posesión y disfrute de un objeto, se frustra, aunque persista en sus asedios, a causa del rechazo virtual. Por eso también este discurso ensaya nuevos intentos y re-escribe su texto. Este enfrentamiento, por otra parte, puede ser entendido, en el contexto cultural e histórico del discurso erótico hispanoamericano, como la dialéctica que implica la actualización de un nuevo modelo erótico que propone el texto modernista en la tradición de la castidad del texto romántico.

La re-escritura que estudiaré, y a la que defino como modalidad típica del modernismo, se expresa anafóricamente tanto en el aspecto expresivo como en su estructura profunda. En el nivel expresivo, la recurrencia de los versos 10 y 11 se repite cumpliendo la misma función en tres secciones más del texto ( $v v .24-25,38-39,52-53$ ), y coadyuva a sostener la estructura alterna en la que se disponen las categorías semánticas del deseo y de la frustración. Es decir, frente a la frustración, figurada con el desfallecimiento, el destinador re-escribe su texto del deseo, al que no tan explícitamente como a la frustración, figurada con lo que puede ser la vivificación. Así, la estructura alterna enunciados del desfallecimiento y de la vivificación, en una relación sintagmática e intratextual, que puede ser otra forma de estructura dialógica y dialéctica del erotismo con la castidad. La re-escritura, en su nueva versión, deviene asimismo en el metatexto de la versión original. Lo explico ahora, al analizar el segundo segmento del texto: la argumentación.

\section{ARgUMENTACIÓN: TEXT'OS DE LA RE-ESCRITURA}

Por definición propia del discurso que estudiamos, el fracaso del deseo erótico es desfallecimiento. Existe, por tanto, en el nivel semántico, una relación de concomitancia entre los semas virginidad y desfallecimiento, a los cuales el discurso erótico propone, en su segundo segmento (vv. 1239), otro sema: el de la vivificación.

\section{Blanco y rosa}

es tu cuerpo harmonioso joh virgen blanca!

Cruzan por él, temblorosas y sutiles, 
En las nacientes colinas,

sobre la nieve, botones de rosa se alzan,

$\mathrm{y}$ hay alburas

de cisnes en tu garganta.

20 ¿Por qué no juegan Amores y Deseos

con los botones de rosa que sobre tu seno se alzan?

¿Por qué los besos

no corren sobre tu cuerpo por tus venas azuladas?

Desfallece

25 como un crepúsculo el eco de las palabras.

En tus labios hay caricias,

moribundas, como una larga esperanza;

en tus ojos hay ensueños

que velan la azul aurora de tu mirada.

30 A tu oído

suspirantes voces hablan,

como murmullo de olas

lejanas.

¿Por qué la abeja no busca

35 la miel que tus labios entreabiertos guardan?

¿Por qué no junta tu Ensueño

con otro Ensueño tus alas?

Desfallece

como un crepúsculo el eco de las palabras.

La estructura estrófica de este segmento se divide según dos referentes principales: 1 el cuerpo, y 2) el rostro de la virgen. Veremos por separado ambas partes.

\section{Texto y metatexto del cuerpo}

La primera parte (vv. 12-25) describe el cuerpo de la joven mediante un estilo impresionista, por el cual crea dos planos referenciales muy típicos del modernismo: uno superficial y aparente, de figura paisajística, y otro subyacente, cuyo referente es el cuerpo femenino como tal. La figura impresionista del plano superficial se produce sobre la fijación imprecisa, parcial, transitoria e inestable de elementos desprendidos y aislados del objeto de observación. Esta fijación selectiva de sólo escasos elementos conlleva una abstracción del objeto (el cuerpo femenino), que permanece segregado de lo concreto, puesto que ese conjunto selectivo de elementos crea su propio referente. El enunciado cuyo sujeto son las sierpes azuladas que cruzan 'temblorosas y sutiles' y los botones de rosa 
que se alzan sobre 'nacientes colinas', crean su propio referente paisajístico, obviamente, que se superpone al referente subyacente del cuerpo de la mujer. Los elementos desprendidos y aislados en el enunciado impresionista pueden ser reconocidos como elementos liberados, y que adquieren autonomía propia. Aquí radica precisamente el aspecto creativo del estilo modernista.

En este sentido se puede señalar en el impresionismo modernista características similares a las que Schmalenbach ha reconocido para el arte pictórico. Ha escrito que «los impresionistas extraen de la naturaleza una pintura que carece de objeto» y que en stis obras se reconoce una "reacción contra los objetos. Apariencia que desconoce los objetos, sin sentido, pura apariencia desvinculada del sentido, cuadros carentes de objeto» («Impresionismo», p. 354). Así también, en el discurso modernista, como se observa claramente en el texto de Jaimes Freyre, la reacción contra el objeto y su desconocimiento da lugar a una dicotomía expresiva (o pluralidad referencial) ${ }^{7}$. Sin embargo, el plano superficial no puede liberarse completamente del referente subyacente y básico. Así se conserva la correlación estricta entre ese plano superficial [P] y el referente subyacente $[R]$ :

[P] sierpes, colinas, botones de rosa, nieve, alburas.

[R] venas, senos, pezones, piel blanca, cuello.

Los dos planos constituyen la escritura y la re-escritura interpretativa y descriptiva (el texto y el meta-texto) de un mismo referente, lo que equivale también a reconocer una doble lectura del cuerpo de la mujer. Se observa el mismo recurso, respecto a un tema similar, en «Blasón», de Darío, donde los campos y las colinas corresponden también a la vestidura y los senos de Leda: «Es el cisne, de estirpe sagrada, / cuyo beso, por campos de seda, / ascendió hasta la cima rosada / de las dulces colinas de Leda» (Prosas profanas).

Ambos planos (o textos, o lecturas) cumplen funciones específicas, según su aspecto expresivo, en la estructuración semántica de este discurso. Orientan el paso de la intención desiderativa del discurso desde la potencia al acto. El texto paisajístico o meta-texto, por un lado (con sus sierpes temblorosas, colinas nacientes, nieve, botones de rosa, alburas), es un enunciado de función atributiva, que enuncia la potencia del objeto contemplado para el estado erótico y su disposición al acto amatorio. E1

${ }^{7}$ De esta característica de la escritura del modernismo me he ocupado en otro lugar («Función transformacional del significante en el discurso modernista», en Hispania [mayo-septiembre 1987], pp. 231-239). 
texto subyacente, por otro lado, con sus proposiciones interrogativas, además de recuperar el objeto segregado por la enunciación anterior, expresa la retórica de la incitación. Todo el sentido de la persuasión erótica se proyecta desde los interrogantes que exhortan al juego y al roce lúbrico, en una expresión audaz y refinada. E1 discurso incita, mediante su función conativa (y aquí radica la magnitud de la vivificación referida), al ejercicio de la caricia sobre los senos desnudos de la joven, descritos en sus detalles anatómicos, así como al roce prolongado de los labios del amante sobre el cuerpo femenino. Empero, los enunciados interrogativos no provocan ninguna respuesta y la vivificación se interrumpe, dejando incumplido el deseo. La vivificación cede su lugar, entonces, al fracaso: el eco desfalleciente de la voz que incita al amor.

\section{Lecturas del rostro}

El discurso ensaya un nuevo intento y una nueva re-escritura del texto, cuya descripción se circunscribe al rostro de la joven (y aquí entramos a tratar la segunda parte del segmento, vv. 26-39). Como en la primera parte de este segmento, también aquí se pueden señalar las dos fases de la retórica de este discurso persuasivo. Un primer enunciado descriptivo, que equivale a la lectura interpretativa del rostro del destinatario y cuya función atributiva es señalar la capacidad para el acto amatorio (la potencia); un segundo enunciado interrogativo, cuya función, consecuente del anterior, demanda la ejecución del mismo acto amatorio. El nivel semántico de la fase descriptiva muestra la concomitancia ya señalada de los semas virginidad y desfallecimiento, de la cual paso a ocuparme.

La virginidad es para este discurso un estado de modorra, insensibilidad, enajenamiento del ánimo. Ese estado se hace evidente por el aletargamiento de los sentidos. La descripción impresionista diseña (lee/escribe) el rostro de la joven mediante la modalidad del enunciado, que desprende y aísla elementos del objeto que subyace en la contemplación (labios, ojos, mirada, oído), a los cuales ordena en la cadena significante de la lectura/ escritura y los relaciona con las potencias sensoriales (táctil, visual, auditiva) en el nivel del significado. Sin embargo, en este mismo nivel del significado, esas potencias se muestran ligadas a isotopías que integran el campo semántico del aletargamiento: lo moribundo, el ensueño, la lejanía. Los labios, en su función de agentes del beso y potencia táctil, refieren lo moribundo; los ojos, en su función visual, la ensoñación, y el oído, en su función auditiva, la lejanía (valores privilegiados por el romanticismo y que para el modernismo son obstáculos de la práctica erótica).

Empero, para este discurso (o lectura interpretativa), ese estado letár- 
gico o de desfallecimiento puede ser, como la virginidad, transitorio. Pues las caricias, aunque moribundas, son una 'larga esperanza', y la mirada, aunque entre ensueños, es una 'azul aurora'. Es decir, esperanza como potencia de deseo y aurora como principio de realización. Sobre estos rasgos (obtenida en una lectura interpretativa del enunciador), la retórica del discurso apoya, primero, la función atributiva de cualidades eróticas, y después, la demanda de la ejecución del acto inscrita en el enunciado causal interrogativo.

Pero, como en la primera parte del segmento, los interrogantes no provocan ninguna reacción ni respuesta. $\mathrm{Y}$ el discurso recupera el tema diseminado de la inutilidad de la incitación, pues otra vez 'el eco de las palabras desfallece como un crepúsculo'.

\section{Prueba: el entimema}

El enunciador abandona el contexto inmediato de su enunciación y acude a un contexto semiótico más amplio para obtener un silogismo retórico y tratar de lograr el convencimiento definitivamente. Así, una vez más intenta re-escribir su discurso, coadyuvado por el argumento de un enthymema, para obtener la respuesta positiva a su persuasión. Ese silogismo retórico le permite demostrar su argumentación en el segmento final del discurso (vv. 40-53). Silogiza con un topos de la antigua retórica y que ha sido recogido y conservado por la tradición de la literatura hispánica: el carpe diem, consagrado por Horacio (Odas, I, 11, 8). El recurso de la re-escritura de lecturas y textos precedentes tiene especial importancia para el modernismo, puesto que ha sido una de sus fuentes creativas. La complejidad del modernismo hispanoamericano radica precisamente en el carácter de palimpsesto que encierra su estructura. Lo he descrito, en el apartado anterior, en los planos textuales e interiores del propio discurso. Lo analizaré luego en su relación exterior con un discurso. ajeno.

El segmento final de «Voz extraña...» es el siguiente:

40 La sangre de las rosas

no dura siempre y las rosas se apagan,

dibuja junto a los labios

un surco la risa amarga;

los ojos y las mejillas

45 son caminos de las lágrimas.

en tu cuerpo,

donde el triunfo de la curva la suma Belleza exalta, 
pondrá el invierno sus hielos mañana.

50 ¡Oh, el calor de las caricias! ¡Oh, los besos!...
Desfallece
como un crepúsculo, el eco de las palabras.

La elección del entimema, cuyo objetivo es la reflexión sobre la condición temporal y sus consecuencias en la naturaleza humana, tiene que ser visto en este discurso de Jaimes Freyre como la re-escritura de un enunciado referido y reflejado por una multiplicidad de textos. En el marco de esa intertextualidad se señalan los motivos ya tradicionales de la fugacidad del tiempo, la transitoriedad de la juventud y belleza naturales y humanas, subrayando el curso inexorable del ser hacia la vejez. Por eso prevalece en este segmento el texto de la decadencia y ruina del ser humano, que contrasta con los segmentos anteriores, en los que el discurso exalta el texto del apogeo del cuerpo en su energía, perfección y belleza. Esa función contrastante de los textos en un mismo discurso sostiene implícitamente una estructura dialéctica que argumenta la persuasión.

El segmento final congrega las isotopías del acabamiento y la transitoriedad («la sangre en las rosas / no dura siempre»), de la extinción («las rosas se apagan»), de la contrariedad existencial («la risa amarga»), de la pesadumbre («las lágrimas») y de la extinción de los sentimientos («pondrá el invierno sus hielos»).

El entimema, como lo quería la retórica tradicional, pide al oyente que obtenga sus propias conclusiones de topos referido ${ }^{8}$, que es a un tiempo comprobación y ejemplo en su carácter de prueba lógica.

\section{El discurso erótico de la intertextualidad}

El entimema en el discurso de Jaimes Freyre no sólo es un topos del cual el enunciado extrae proposiciones de argumentación en silogismo incompleto para la retórica de su persuasión, sino motivo de una nueva relación meta-textual mediante la re-escritura. El topos horaciano del carpe diem es obtenido, como trataré de demostrar, de un soneto de Garcilaso. Subrayo este hecho como producto de la actitud filológica modernista, que cultiva la re-escritura en la intertextualidad. Esta especie de

${ }^{8}$ Cito esta definición de Forma praedicandi (1322), de Roberto de Basevorn. Véase Murphy (La Retórica de la Edad Media, trad. de G. Hirata Vaguera [México: F. C. E., 1986], p. 358). 
variaciones sobre el mismo tema es una característica de la escritura modernista y otro modo de ver la pluralidad referencial aludida.

E1 entimema del carpe diem se remonta a Ausonio y Horacio. Algunos de sus elementos semánticos desembocan en la lírica barroca española. Góngora dedicó dos sonetos al tópico ${ }^{9}$. Sin embargo, creo ver que Jaimes Freyre lo tomó del soneto XXIII de Garcilaso de la Vega, que inspirara asimismo los dos sonetos de Góngora. Salvadas las distancias entre la actitud erótica de dos épocas, la moderación y el decoro del renacimiento y el franco erotismo modernista, es posible establecer una correlación clara entre ambos textos. El poema de Garcilaso (en la versión definitiva señalada por Blecua, pp. 68-71) dice:

En tanto que de rosa y d'azucena se muestra la color en vuestro gesto, y que vuestro mirar ardiente, honesto, con clara luz la tempestad serena;

5 y en tanto que'l cabello, que'n la vena de oro s'escogió, con vuelo presto por el hermoso cuello blanco, enhiesto, el viento mueve, esparce y desordena:

coged de vuestra alegre primavera

10 el dulce fruto antes que'l tiempo airado cubra de nieve la hermosa cumbre.

Marchitará la rosa el viento helado, todo lo mudará la edad ligera por no hacer mudanza en su costumbre.

Algunas comparaciones entre ambos textos son obvias. Así, mientras el tema del carpe diem es explícitamente afirmado por el poeta español (vv. 9-10), el poeta boliviano no lo expresa y, por el contrario, permanece

${ }^{9}$ En el primero, «Mientras por competir con tu cabello» (1528), exhorta a su joven destinataria:

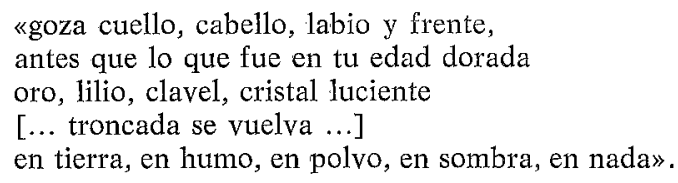

El segundo soneto, «Ilustre y hermosísima María» (1583), dice en su terceto final: «antes de lo que hoy es rubio tesoro venza a la blanca nieve su blancura, goza, goza el color, la luz, el oro». 
latente en las proposiciones interrogativas de su argumentación, sosteniendo los elementos del entimema. Por otra parte, mientras el referente de Garcilaso es el rostro de la joven, en Jaimes Freyre es principalmente el cuerpo desnudo de la mujer. En base a esos referentes se pueden establecer las siguientes correlaciones:

«Soneto XXIII»

piel «de rosa y d'azucena» (v. 3)

mirar «honesto» (v. 3)

«hermoso cuello blanco, enhiesto» (v. 7)

«el viento mueve, esparce, desordena» el cabello (v. 8)

«antes que'l tiempo airado / cubra de nieve» (vv. 10-11)

«Marchitará la rosa», «todo lo mudará la edad ligera» (vv. 12-13)
«Voz extraña...»

«blanco y rosa / es tu cuerpo» (vv. 12-13)

«virgen» (v. 3), «virgen blanca» (v. 13)

«hay alburas / de cisne en tu garganta» (vv. 18-19)

la voz se enredara «en tus trenzas, blondas y largas» (v. 7)

«Pondrá el Invierno sus hielos / mañana» (vv. 48-49)

«La sangre de las rosas / no dura siempre y las rosas se apagan» (vv. 40-41)

Sin embargo, lo que en Garcilaso es apenas una insinuación del deseo erótico contenido, en Jaimes Freyre es una descripción y amplificación irrefrenable, delectación morosa del cterpo femenino desnudo. Mientras el texto renacentista concentra su intención erótica en el mirar «ardiente», que, por una parte, provoca una «tempestad» en los sentimientos deseantes, aunque, por otra, ese mirar, por ser «honesto», serena con su «clara luz» dicha tempestad. En el texto modernista, el cuerpo desnudo de la joven despierta la atracción concupiscente, aunque su estado virginal la rechace. La estructura retórica del discurso renacentista se apoya en sentimientos tanto de provocación como de contenido del deleite. Aquí cabe la gran diferencia. Garcilaso insinúa levemente la provocación al goce e inspira enfáticamente al refrenamiento. Recuérdese que este poeta parece haber intentado una segunda redacción precisamente del verso 4 . En esa segunda versión atendió fundamentalmente los verbos, es decir, la acción. Introdujo el verbo «encender» y sustituyó "serenar», tan atenuado en su intención semántica, por otra más enérgico, «refrenar». E1 nuevo verso dice: «enciende el corazón y lo refrena» ${ }^{10}$. Jaimes Freyre expresa franca y detalladamente la incitación al placer sensual, en la que no cabe la contención.

${ }^{10}$ Para la discusión de esa variante véase Alberto Blecua, En el texto de Garcilaso (Madrid: Insula, 1970), pp. 70-71. 


\section{CONCLuSión}

El discurso erótico de Jaimes Freyre demuestra claramente las innovaciones que introduce el modernismo en aspectos esenciales de la expresión y el contenido de la poesía hispanoamericana de fines del siglo XIX. El modernismo, preocupado hondamente por la realidad metafísica del mundo de las apariencias, y ante la imposibilidad de descubrirla en su índole esencial, ha cultivado, paradójicamente, el goce sensual como la consecuencia inmediata del limitado conocimiento humano, meramente perceptual y fenoménico ${ }^{11}$. Ante el convencimiento de que el conocimiento intelectivo es siempre restringido y finito, se ha entregado a la experiencia sensible. De ese contexto surge su discurso erótico como lenguaje que explica una conciencia alerta y por el que ésta se expresa mejor. No en vano, como lo vemos en Jaimes Freyre, el discurso erótico modernista es una delectación morosa de la sensualidad libre y gozosa, aunque paradójicamente limitada y frustrante, en una lucha constante de dos elementos en pugna, philo y phobia; lucha que representa asimismo la dialéctica del discurso erótico modernista por instituir su código hedonista y sensual sobre la tradición romántica del decoro y la castidad. Tal es la esencial diferencia entre el erotismo romántico y modernista en la poesía hispánica. Si el primero busca la trascendencia del espíritu hacia el ideal divino, el segundo busca la trascendencia de la carne hacia el espíritu humano.

${ }^{11}$ Me he ocupado ampliamente de este aspecto en los capítulos sobre el modernismo de mi libro de 1988, La poesía hispanoamericana del siglo XIX (Madrid: Alhambra, 1988). 